\title{
Effects of Supersonic Vibration Field on Flow Characteristics and Filling Behavior of Glass-fiber-enhanced Polybutylene Terephthalate Microstructural Injection Molding Melt
}

\author{
Shasha Wei, ${ }^{1}$ Yifan Yin, ${ }^{2}$ Junrong Chen, ${ }^{1}$ and Rongchuan Lin $^{1 *}$ \\ ${ }^{1}$ School of Mechanical and Energy Engineering, Jimei University, Xiamen, Fujian 361021, China \\ ${ }^{2}$ Xiamen SonglinTechnology Co., Ltd., Xiamen, Fujian 361026, China
}

(Received May 31, 2019; accepted September 9, 2019)

Keywords: thin-walled microstructural plastic part, microinjection molding, supersonic vibration field, sensor, cavity pressure curve collection

In this paper, the injection molding process parameter determination method based on computer-aided engineering (CAE) and orthogonal experiments is adopted to study the microstructural cavity of the modified glass-fiber-enhanced polybutylene terephthalate (PBT) subjected to severe short shots under conventional injection molding conditions. Cavity pressure is accurately controlled by monitoring the cavity pressure curve. At the same time, the parameters of injection molding technology were optimized. The effect of the supersonic vibration field on the flow behavior of the glass-fiber-enhanced PBT microstructural injection molding melt was analyzed. The effects of the conventional forming process and supersonic vibration on the quality and properties of injection molding were also examined. The results suggest that the supersonic vibration field could not only lower the viscosity of the polymer melt and increase its fluidity but also enhance the mechanical properties of the products, reduce buckling deformation, and improve the appearance and filling quality of the products.

\section{Introduction}

With its good mechanical and electric properties, the modified glass-fiber-enhanced polybutylene terephthalate (PBT) is an ideal engineering material for manufacturing relay and other electrical components. However, the process of precisely molding glass-fiber-enhanced PBT plastic parts is complex. The polymer melt cools rapidly in the mold cavity and solidifies within a short time, so the molding quality is difficult to control. However, by adding glass fiber, melt viscosity can be increased and fluidity can be reduced. In microinjection molding, because the microstructure plastic part is small, as are the flow channel, the mold cavity, and the injection amount, some factors that could be neglected under routine conditions might have considerable effects on the flow behavior and flow characteristics of the melt when molding microstructure parts. In particular, the microscale effect in molding multicavity microinjection parts could cause changes in the microinjection process and product quality. Deviations of 
the temperature distribution and flow velocity of the melt in a microflow channel could result in discrepancies in the performance, precision, and mass of the molded products in various geometrically symmetrical mold cavities of the same mold. ${ }^{(1-4)}$

Ultrasonic-assisted microinjection molding is a new method of processing microstructural plastic parts developed on the basis of conventional microinjection molding methods. Compared with the conventional methods, the new method has the following advantages. (1) Supersonic vibration not only lowers the viscosity of the polymer melt and increases its fluidity, but also reduces energy consumption and shortens the molding cycle; therefore, it is suitable especially for the microinjection molding of a glass-fiber-enhanced polymer. (2) It could improve the internal microstructure and mechanical properties, reduce buckling deformation, improve the appearance, and enhance the copy precision of products. (3) It could strengthen the compatibility of the blends, promote mutual diffusion and integration between various component material molecules, and enhance the mechanical properties of the blend products. (4) It could improve the plastification quality of the polymer melt. Compared with the conventional heating plasticizing method, supersonic plastification has the advantages of high quality, low energy consumption, less friction loss, cleanliness, and high efficiency; therefore, it is more suitable for precise microinjection molding. ${ }^{(5)}$

Although the supersonic-assisted microinjection technology has developed rapidly in recent years, it is still immature and remains in the development stage, facing many difficulties. At present, studies conducted both at home and abroad have solved to some degree the relevant theories and processing problems of the flow behavior and characteristics of the microstructural injection melt; however, the viscosity model of the rheological behavior of the microscale melt still could not be represented correctly such that the accuracies of the velocity, temperature, and stress fields obtained through numerical simulation could not be guaranteed, which could affect the quality prediction accuracy of microplastic parts. ${ }^{(6-8)}$ Although scholars at home and abroad have conducted much research to study the heat convection behavior under microscale conditions, most of them studied only Newtonian fluids such as gas and water, and there are only a few studies on the heat convection behavior of non-Newtonian polymer melt in the microscale.

In addition, since the pressure curve of the molding cavity reflects actual changes in the polymer melt in the molding cavity during injection molding, if the pressure curves of the molding cavity during two injection processes are basically the same, then the products obtained during two injection processes will have similar qualities. The establishment of a cavity pressure measurement system can realize the accurate monitoring and control of the injection mold cavity pressure. However, there are only a few studies on the monitoring of the microscale injection molding cavity pressure curve.

The effects of the supersonic vibration field on the flow behavior of glass-fiber-enhanced PBT microstructural injection melt were studied and analyzed using the Cross-WilliamsLandel-Ferry (WLF) model as the basis in this study. We fit and modified the viscosity model of the flow behavior of the macromelt by monitoring and controlling the microstructural injection molding flow conditions, such as melt temperature, relative molecular mass, shearing rate, and cavity pressure curve. By the injection molding parameter determination method 
based on computer-aided engineering (CAE) and orthogonal experiments and with thin-walled mold cavities that exhibit short shots under common injection conditions, the rules of the injection molding parameters and their effects on the quality of thin-wall microinjection molds were studied by comparing the masses of the parts with short shots and the maximum wall shear stresses at different locations. The technological parameters obtained were optimized to determine the optimal thin-wall plastic microinjection molding process parameters under the current conditions.

The supersonic-assisted thin-wall microinjection molding system is used for thin-wall injection molding experiments to study the supersonic-assisted molding technology and the effects of a supersonic wave on the mold filling property of high polymer melt as well as the properties of the molded parts. We aim to further promote the development and diversity of thin-wall microinjection molding technology.

\section{Effects of Supersonic Vibration Field on Flow Characteristics of Microstructural Injection Melt and Factors Influencing Flow Characteristics}

A supersonic vibration field is applied in the plastification of polymers. The high-frequency vibration of a supersonic wave squeezes and releases the polymer melt continuously and reduces the interaction between molecules such that the plastification of polymer materials becomes more thorough and the flow properties of the polymer melt can be improved. In this manner, the mathematical model of the flow of the supersonic-assisted polymer melt in a microflow channel could be established and the problem of uneven filling in injection molding could be solved.

\subsection{Effects of supersonic vibration field on polymer melt temperature}

The flow of the polymer melt is a flow and heat transfer process of a non-Newtonian fluid under a supersonic vibration field; it is a non-Newtonian compressible non-isothermal transient nonsteady-state process in the runner. In polymer injection molding, temperature control is one of the essential means of regulating the fluidity of high polymer melt. With the increase in melt temperature, the interaction between the macromolecular chains of the high polymer melt weakens, resulting in a decrease in the viscosity of the melt. ${ }^{(9,10)}$

When the temperature of the high polymer melt is $T>T_{g}+100{ }^{\circ} \mathrm{C}$, the dependence of melt viscosity on temperature can be represented by the Arrhenius mathematical model. ${ }^{(5)}$ In the case of a constant shearing rate, the dependence of melt viscosity on temperature is as shown in Eq. (1), but in the case of a constant shearing stress, it is as shown in Eq. (2):

$$
\begin{aligned}
& \eta=A \exp \left(E_{\gamma} / R T\right), \\
& \eta=A^{\prime} \exp \left(E_{\tau} / R T\right),
\end{aligned}
$$


where $A$ and $A^{\prime}$ are viscosity constants (PA's), $E_{\gamma}$ is the viscous flow activating energy at a constant shearing rate, and $E_{\tau}$ is the viscous flow activating energy under a constant shearing stress. $R$ is the universal gas constant $(8.32 \mathrm{~J} / \mathrm{mol} \cdot \mathrm{K})$ and $T$ is the thermodynamic temperature $(\mathrm{K})$.

Take the logarithm of Eqs. (1) and (2), and the formulas are respectively changed into

$$
\begin{aligned}
& \ln \eta=\ln A+\frac{E_{\gamma}}{R T}, \\
& \ln \eta=\ln A^{\prime}+\frac{E_{\tau}}{R T} .
\end{aligned}
$$

In the low temperature range of $T-T_{g}+100{ }^{\circ} \mathrm{C}$, the WLF equation could be used to describe the relationship between the viscosity and temperature of the high polymer melt, as shown by

$$
\ln \eta_{g}=\ln \eta_{g}-\left[\frac{17.44\left(T-T_{g}\right)}{51.6+\left(T-T_{g}\right)}\right],
$$

where $\eta_{g}$ is the viscosity at temperature $T_{g}$.

Because the injection structure of the microstructural plastic parts is small and the flow channel is miniaturized, the flow of the fluid in the microflow channel is different from that in the flow channel of normal size, and the surface area-to-volume ratio of the channel increases; therefore, it is difficult for the macroviscosity model to describe correctly the flow, behavior of the melt in the microscale. Some influencing factors that are neglected in the macroscale could play significant roles in the injection molding of microstructural plastic parts. Thus, it is necessary to add dimensional correction factors, molecular orientation-influencing factor and the temperature correction factor of the microchannel to modify the Cross-WLF parameter model. The viscosity model of the flow behavior of the microstructural injection molding melt is obtained as ${ }^{(11,12)}$

$$
\begin{gathered}
\eta=\frac{\eta_{0}}{1+\left(\frac{\eta_{0}}{\tau} \gamma\right)^{1-n}}, \\
\eta_{0}=D_{1} \exp \left[\frac{-A_{1}\left(T-T^{*}\right)}{A_{2}+\left(T-T^{*}\right)}\right],
\end{gathered}
$$

where $T^{*}=D_{2}+D_{3} p$ and $A_{2}=\tilde{A}_{2}+D_{3} p . D_{1}, D_{2}, D_{3}, A_{1}$, and $\tilde{A}_{2}$ are modulus constants. 


\subsection{Effects of supersonic vibration field on relative molecular mass}

The flow of the high polymer melt displaces the molecule gravity towards the flow direction. ${ }^{(7,8)}$ The larger the relative molecular mass of the high polymer, the longer the molecular chain and the more chain segments it contains, which makes the flow displacement more difficult. Thus, the viscosity of the high polymer melt would increase with the relative molecular mass. However, in the process of applying the supersonic wave in the high polymer melt, the molecular chain cracks and the average relative molecular mass of the molecules of the high polymer melt decreases gradually with increasing action time between the supersonic wave and the high polymer melt. On the other hand, the macromolecular chain of the high polymer melt cracks with a decrease in the function of the supersonic wave, resulting in the high polymer melt viscosity. ${ }^{(7,8)}$

\subsection{Effects of supersonic vibration field on shearing rate}

A significant characteristic of the high polymer melt is its non-Newtonian behavior, that is, its viscosity decreases with increasing shearing rate. ${ }^{(7,8)}$ The melt viscosity at a low shearing rate is several orders of magnitude larger than that at a high shearing rate. With the increase in the shearing rate during the flow process, the extent of the decrease in viscosity of the high polymer melt also varies. It could be considered that, in injection molding, the relationship between the melt viscosity and the shearing rate obeys the power law relation shown by

$$
\eta=K \gamma^{n-1}
$$

Here, $n$ is the non-Newtonian index, which reflects the sensitivity of the melt viscosity to the shearing rate to some degree.

Generally, within the temperature range of plastic melting and when the shearing rate of the melt is $10^{3}-10^{4} \mathrm{~s}^{-1}$, the power law index $n$ is within $0-1$.

It could be seen from Eq. (8) that the melt viscosity could be reduced by increasing the shearing rate; however, this reducing effect depends on the value of $n$, i.e., the sensitivity of materials to the shearing rate.

After the supersonic vibration field is added, the polymer melt in the microflow channel flows forward at the fluctuation velocity, increasing the mutual shearing friction between macromolecular chains, so the velocity of the polymer melt decreases gradually with the flow of the melt. On the other hand, the high-frequency wave propagation of the polymer melt in the microflow channel could change the molecular orientation of the macromolecular chains and affect the quality of injection molding. ${ }^{(13,14)}$ 


\subsection{Analysis of influence of pressure on fluid viscosity and monitoring method based on cavity pressure curve}

\subsubsection{Analysis of the effect of pressure on fluid viscosity}

It is generally considered that the effect of pressure on the polymer flow viscosity is of considerable importance. Fluid viscosity depends on the force acting between molecules, which is related to the distance between molecules. When the melt is subjected to external pressure, the free volume and the distance between macromolecules will decrease, which leads to the increase in both the interaction force between macromolecules and melt viscosity.

At present, the mathematical relational expression between viscosity and pressure recognized by scholars worldwide is as shown in Eq. (9), which was put forward by Hirai and Eyring on the basis of Eyring's flow hole theory. ${ }^{(7,8)}$

$$
\eta_{P}=\eta_{p 0} \exp \left[\beta\left(p-p_{0}\right)\right]
$$

Here, $\eta_{P}$ is the melt viscosity under pressure $P, \eta_{p 0}$ is the melt viscosity under barometric pressure, and $\beta$ is the pressure factor.

After the supersonic vibration field is added, low-pressure and high-pressure regions are formed in the pressure field. The melt fluctuation frequency in the microflow channel increases with increasing supersonic frequency, and the viscosity of the polymer melt also increases.

\subsubsection{Monitoring method based on cavity pressure curve}

The cavity pressure measurement is a method of recording and analyzing the actual change information of the melt in the injection process by measuring the pressure of the polymer melt in the mold cavity. By monitoring and adjusting the cavity pressure curve, the process parameters can be rapidly and accurately optimized, and the quality of products can be improved. Figure 1 shows a schematic diagram of the cavity pressure measurement system. After the pressure signal is measured by the pressure sensor, it is converted into a digital signal by an A/D converter, and the collected data is appropriately amplified by a signal amplifier. After the collected data is input into each module of the software system, the pressure of the mold cavity can be accurately controlled by monitoring the mold cavity pressure curve.

\section{Optimization of Plastic Microinjection Molding Process Parameter}

The effects of the conventional technological parameters on the glass-fiber-enhanced PBT filling thin-wall cavity was studied by the injection molding parameter determination method based on CAE and orthogonal experiments. The thin-wall parts with short shots under common injection conditions were used as mold cavities. The rules of the injection molding parameters and their effects on the quality of thin-wall plastic microinjection molds 


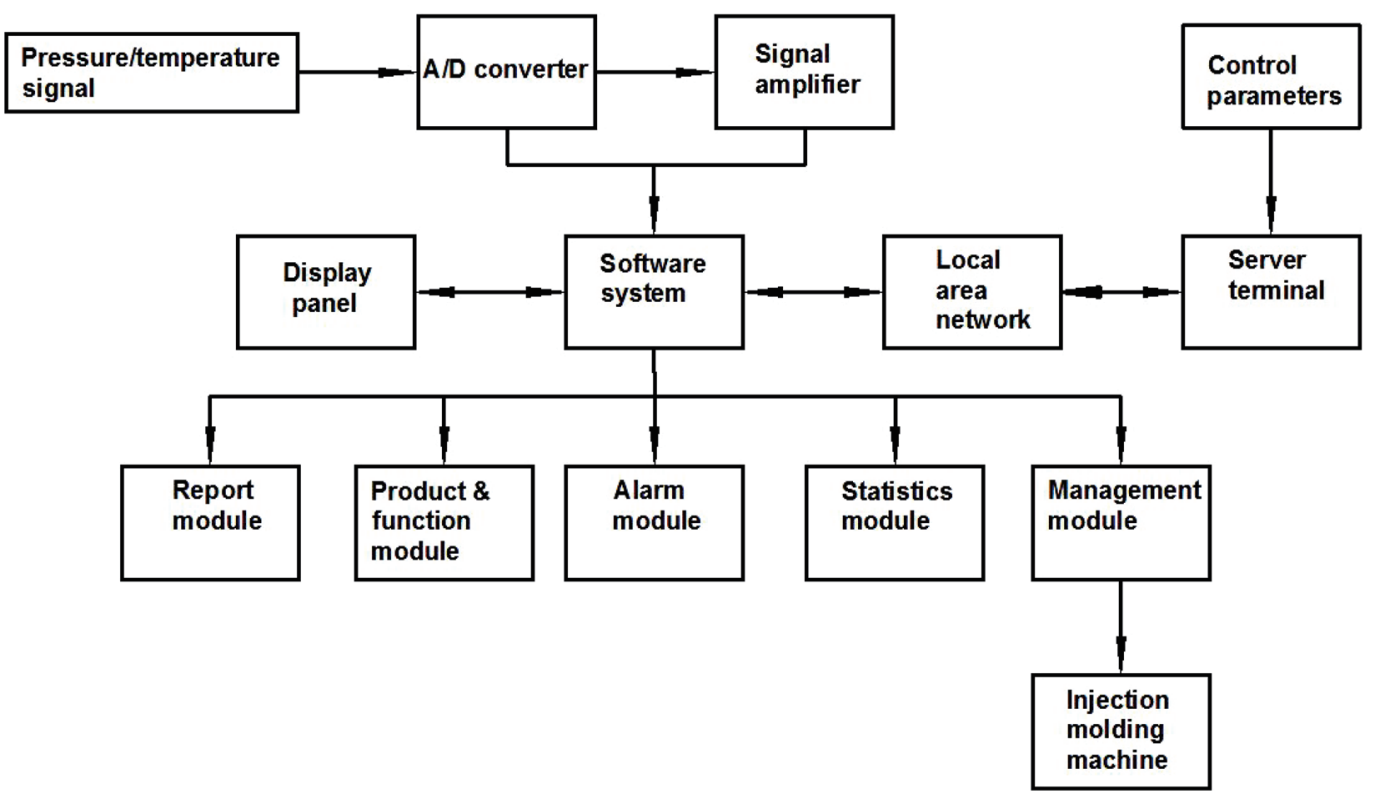

Fig. 1. Cavity pressure measurement system.

were studied by comparing the masses of the parts when a short shot occurs and the maximum value of wall shear stress at different locations. The thin-wall plastic microinjection molding process parameters obtained under the current conditions were optimized to serve as references of technological parameters for subsequent supersonic thin-wall microinjection molding experiments.

\subsection{Determination of simulation experimental material}

The simulation material used in the subsequent experiments was modified glass-fiberenhanced PBT with a glass fiber filling level of 30\% (SABIC Innovative Plastics US LLC; mark number Valox420SEO). Some essential properties of the material are shown in Fig. 2 and Tables 1-4.

\subsection{Description of experimental products}

Short shots are among the most serious defects of injection molding. In thin-wall microinjection molding, the workpiece is very thin, so the resistance in the filling cavity would be very large. If the fluidity of the high polymer melt is poor, there is a very high possibility of the occurrence of short shots. In this experiment, to better analyze the experimental results, a cavity that naturally had short shots under common injection technological conditions were selected as the object of the experiment. The filling fluidity of the modified glass-fiberreinforced PBT and the microstructural changes of the plastic parts were compared under supersonic and nonsupersonic conditions. The thin-wall products of $0.3 \mathrm{~mm}$ thickness, as shown in Fig. 3, were used in this experiment. 

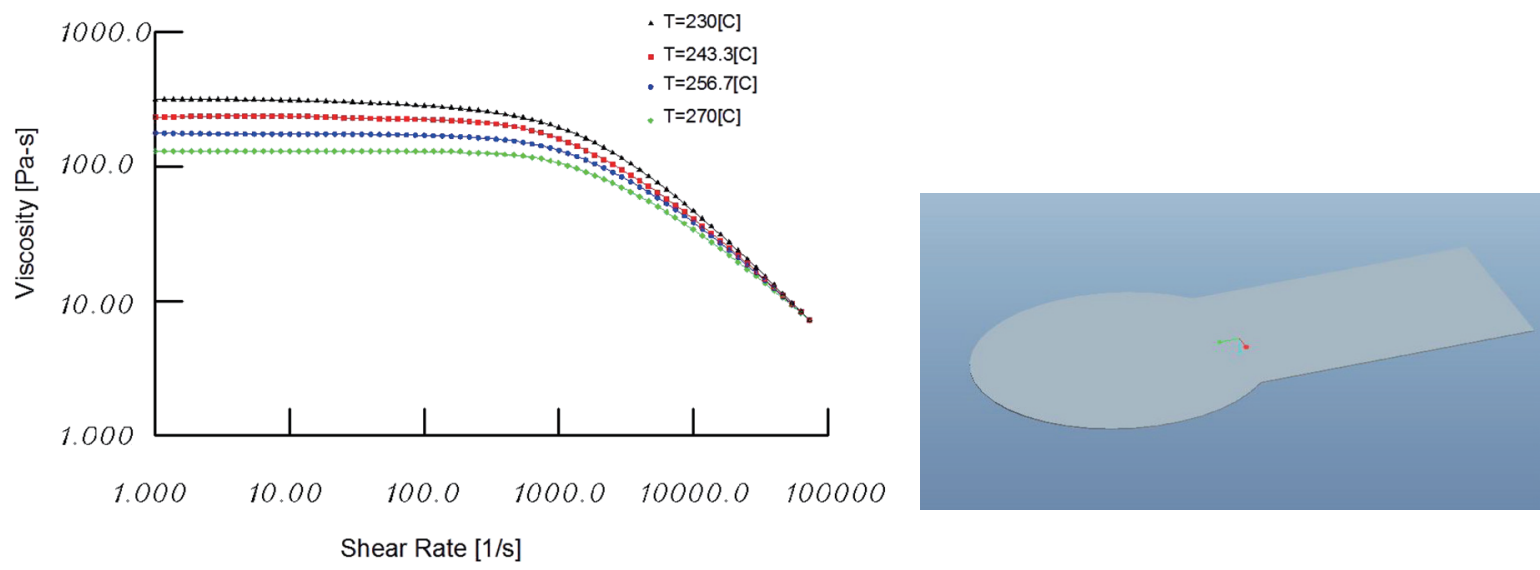

Fig. 2. (Color online) Curve of material viscosity.

Fig. 3. (Color online) Product outline drawing.

Table 1

Recommended processing of the material.

\begin{tabular}{|c|c|c|c|c|c|c|c|c|c|}
\hline \multirow{2}{*}{$\begin{array}{c}\text { Mold surface } \\
\text { temperature } \\
\left({ }^{\circ} \mathrm{C}\right)\end{array}$} & \multirow{2}{*}{$\begin{array}{c}\text { Melt } \\
\text { temperature } \\
\left({ }^{\circ} \mathrm{C}\right)\end{array}$} & \multicolumn{2}{|c|}{$\begin{array}{c}\text { Mold } \\
\text { temperature } \\
\text { range }\left({ }^{\circ} \mathrm{C}\right)\end{array}$} & \multicolumn{2}{|c|}{$\begin{array}{c}\text { Melt } \\
\text { temperature } \\
\text { range }\left({ }^{\circ} \mathrm{C}\right)\end{array}$} & \multirow{2}{*}{$\begin{array}{l}\text { Absolute } \\
\text { maximum } \\
\text { melt } \\
\text { temperature } \\
\left({ }^{\circ} \mathrm{C}\right)\end{array}$} & \multirow{2}{*}{$\begin{array}{c}\text { Ejection } \\
\text { temperature } \\
\left({ }^{\circ} \mathrm{C}\right)\end{array}$} & \multirow{2}{*}{$\begin{array}{c}\text { Maximum } \\
\text { shear stress } \\
\quad(\mathrm{MPa})\end{array}$} & \multirow{2}{*}{$\begin{array}{c}\text { Maximum } \\
\text { shear rate } \\
(1 / \mathrm{s})\end{array}$} \\
\hline & & Min & Max & Min & Max & & & & \\
\hline 60 & 250 & 40 & 80 & 230 & 270 & 290 & 185 & 0.4 & 50000 \\
\hline
\end{tabular}

Table 2

Rheological properties of the material.

\begin{tabular}{|c|c|c|c|c|}
\hline \multirow{2}{*}{$\begin{array}{l}\text { Default viscosity } \\
\text { model }\end{array}$} & \multicolumn{2}{|c|}{$\begin{array}{c}\text { Junction loss } \\
\text { method coefficient }\end{array}$} & \multirow{2}{*}{$\begin{array}{c}\text { Transformation } \\
\text { temperature } \\
\left({ }^{\circ} \mathrm{C}\right)\end{array}$} & \multirow{2}{*}{$\begin{array}{l}\text { MOLDFLOW } \\
\text { viscosity index }\end{array}$} \\
\hline & $\mathrm{cl}\left(\mathrm{Pa}^{(1-\mathrm{c} 2)}\right)$ & $\mathrm{c} 2$ & & \\
\hline Cross-WLF & 27.99 & 0.9903 & 205 & VI(250)0103 \\
\hline
\end{tabular}

Table 3

PVT properties of the material.

\begin{tabular}{|c|c|c|c|c|c|c|c|c|c|c|c|c|c|c|}
\hline \multirow{2}{*}{$\begin{array}{c}\text { Melt } \\
\text { density } \\
\left(\mathrm{g} / \mathrm{cm}^{3}\right)\end{array}$} & \multirow{2}{*}{$\begin{array}{c}\text { Solid } \\
\text { density } \\
\left(\mathrm{g} / \mathrm{cm}^{3}\right)\end{array}$} & \multicolumn{13}{|c|}{ Two-domain modified Tait pvT model coefficients. } \\
\hline & & $\begin{array}{l}\mathrm{b5} \\
(\mathrm{K})\end{array}$ & $\begin{array}{c}\mathrm{b} 6 \\
(\mathrm{~K} / \mathrm{Pa})\end{array}$ & $\begin{array}{c}\mathrm{b} 1 \mathrm{~m} \\
\left.\mathrm{~m}^{3} / \mathrm{kg}\right)\end{array}$ & $\begin{array}{c}\mathrm{b} 2 \mathrm{~m} \\
\left(\mathrm{~m}^{3} / \mathrm{kg}-\mathrm{K}\right)\end{array}$ & $\begin{array}{l}\mathrm{b} 3 \mathrm{~m} \\
(\mathrm{~Pa})\end{array}$ & $\begin{array}{l}\mathrm{b} 4 \mathrm{~m} \\
(1 / \mathrm{K})\end{array}$ & $\begin{array}{c}\mathrm{b} 1 \mathrm{~s} \\
\left(\mathrm{~m}^{3} / \mathrm{kg}\right)\end{array}$ & $\begin{array}{c}\mathrm{b} 2 \mathrm{~s} \\
\left(\mathrm{~m}^{3} / \mathrm{kg}-\mathrm{K}\right)\end{array}$ & $\begin{array}{l}\mathrm{b} 3 \mathrm{~s} \\
(\mathrm{~Pa})\end{array}$ & $\begin{array}{l}\mathrm{b} 4 \mathrm{~s} \\
(1 / \mathrm{K})\end{array}$ & $\begin{array}{c}\mathrm{b} 7 \\
\left(\mathrm{~m}^{3} / \mathrm{kg}\right)\end{array}$ & $\begin{array}{c}\mathrm{b} 8 \\
(1 / \mathrm{K})\end{array}$ & $\begin{array}{c}\mathrm{b} 9 \\
(1 / \mathrm{Pa})\end{array}$ \\
\hline & 1.6414 & 2.15 & $\begin{array}{c}1.45 \\
E-07\end{array}$ & 4 & $\begin{array}{c}4.33 \\
E-07\end{array}$ & $\begin{array}{c}1.37 \\
E+08\end{array}$ & 03 & .0006484 & $\begin{array}{c}1.92 \\
\text { E-07 }\end{array}$ & $\begin{array}{c}2.17 \\
\mathrm{E}+08\end{array}$ & 1 & $\begin{array}{c}4.33 \\
E-05\end{array}$ & 0622 & $\begin{array}{c}1.06 \\
\mathrm{E}-08\end{array}$ \\
\hline
\end{tabular}

Table 4

Mechanical properties of the material.

\begin{tabular}{ccccccc}
\hline \multicolumn{3}{c}{ Mechanical properties } & & \multicolumn{2}{c}{$\begin{array}{c}\text { Transverse isotropic coefficient } \\
\text { of thermal expansion data }\end{array}$} \\
\hline $\begin{array}{c}\text { Elasticity } \\
\text { modulus (E1) }\end{array}$ & $\begin{array}{c}\text { Elasticity } \\
\text { modulus } \\
(\mathrm{E} 2)\end{array}$ & $\begin{array}{c}\text { Poisson's } \\
\text { ratio (v12) }\end{array}$ & $\begin{array}{c}\text { Poisson's } \\
\text { ratio (v23) }\end{array}$ & $\begin{array}{c}\text { Shear modulus } \\
(\mathrm{G} 12)\end{array}$ & Alpha1 (1/C) & Alpha2 (1/C) \\
\hline $9610.36 \mathrm{MPa}$ & $5537.35 \mathrm{MPa}$ & 0.4191 & 0.4717 & $2396.64 \mathrm{MPa}$ & $2.27 \mathrm{E}-05$ & $5.12 \mathrm{E}-05$ \\
\hline
\end{tabular}




\subsection{Experimental design}

\subsubsection{Experimental indexes}

When the cavity of the product is too small, the melt undergoes severe shearing action with the surface of the modal cavity during cavity filling, and severe burns of the product surface and degradation of the products easily occur, which could directly affect the mechanical properties and appearance of the products. Therefore, the maximum wall shearing stress at two representative positions was adopted as the index. Positions of N10418 and N11690 are shown in Fig. 4.

\subsubsection{Table of experimental factor levels}

The levels of various factors are shown in Table 5.

\subsubsection{Experimental data}

Moldflow 2012 was used to simulate the injection process of the glass-fiber-enhanced PBT, the method comprising the combination of an orthogonal experiment and Moldflow molding simulation is adopted, and the synthetic weighted scoring method and extremum difference analysis were used to process the orthogonal experimental data. The range chart of various factors in Fig. 5 at different levels and the aggregative indicator summation schematic diagram (Fig. 6 ) were obtained. The impact trends of various factors on the molding quality and the inherent law were analyzed, and the optimal injection molding process parameters of the experimental plastic parts, which were a melt temperature of $280{ }^{\circ} \mathrm{C}$, a die temperature of $40{ }^{\circ} \mathrm{C}$, a dwell pressure of $180 \mathrm{MPa}$, and a screw velocity of $80 \mathrm{~mm} / \mathrm{s}$, were finally determined.

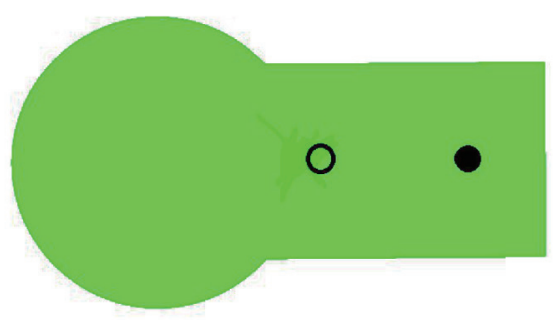

Fig. 4. (Color online) Positions of N10418 (solid circle) and N11690 (open circle).

Table 5

Levels of various factors.

\begin{tabular}{lcccc}
\hline \multirow{2}{*}{ Levels } & \multicolumn{4}{c}{ Factors } \\
\cline { 2 - 5 } & $\mathrm{A}\left({ }^{\circ} \mathrm{C}\right)$ & $\mathrm{B}\left(/{ }^{\circ} \mathrm{C}\right)$ & $\mathrm{C}(\mathrm{mm} / \mathrm{s})$ & $\mathrm{D}(\mathrm{MPa})$ \\
\hline 1 & 250 & 40 & 80 & 120 \\
2 & 280 & 60 & 90 & 150 \\
3 & 310 & 80 & 100 & 180 \\
\hline
\end{tabular}

A: melt temperature, B: mold temperature, C: screw speed, D: dwell pressure 


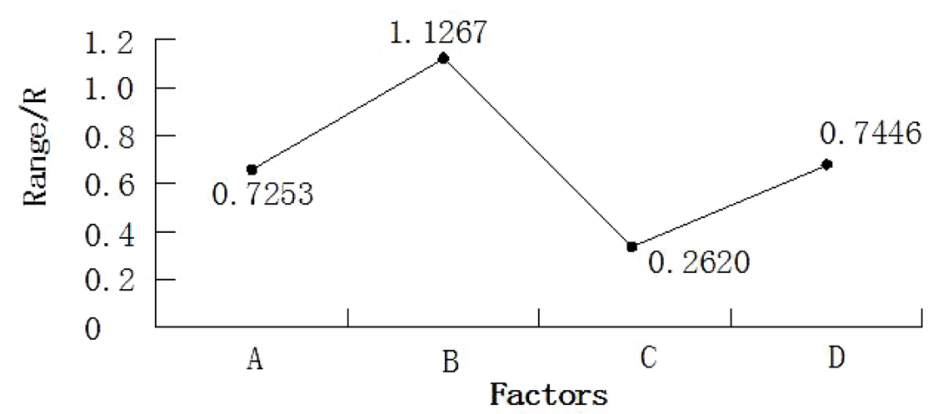

Fig. 5. Factor range line chart.

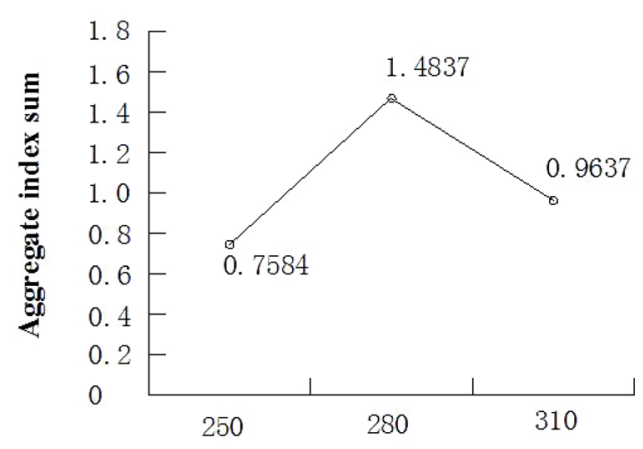

Melt temperature $/{ }^{\circ} \mathrm{C}$

(a)

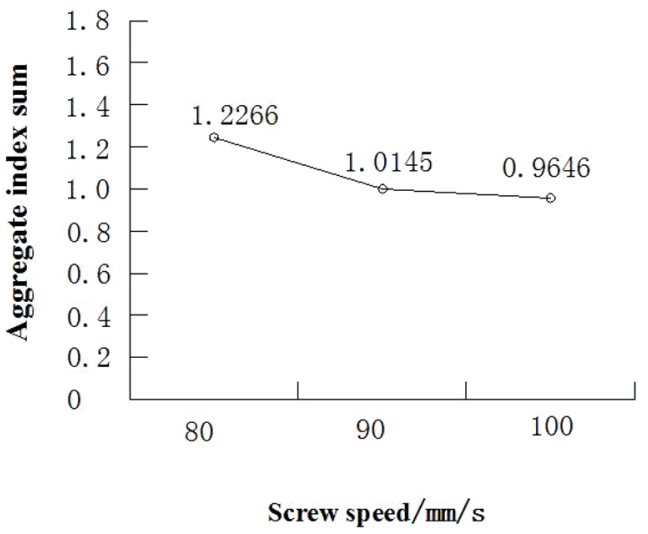

(c)

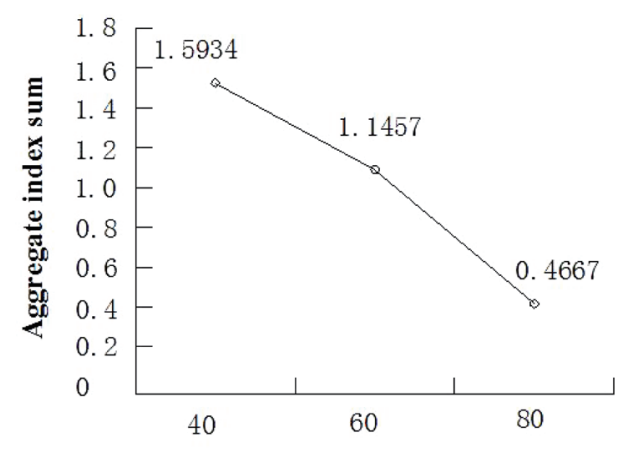

Mold temperature $/{ }^{\circ} \mathrm{C}$

(b)

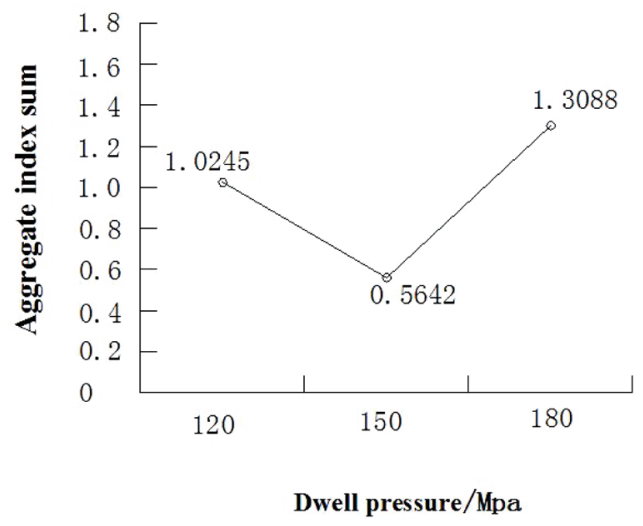

(d)

Fig. 6. Schematic diagram of aggregative indicator summation.

\section{Supersonic-assisted Injection Molding Experiment}

\subsection{Experimental facilities and parameters}

The injection equipment used in this experiment was the WG-80 injection molding machine. In accordance with the optimum technological parameters determined through the orthogonal experiment and the Moldflow analysis mentioned above, the melt temperature was set to 280 ${ }^{\circ} \mathrm{C}$, the die temperature to $65{ }^{\circ} \mathrm{C}$, the screw velocity to $80 \mathrm{~mm} / \mathrm{s}$, the dwell pressure to 180 
$\mathrm{MPa}$, the cooling time to $5 \mathrm{~s}$, and the dwell time to $0.5 \mathrm{~s}$. The injection molding experiment was conducted under the conditions with and without supersonic waves, and the products were collected.

\subsection{Injection molding experiment without supersonic waves}

To avoid the interference of unsteady processing in the experiment, the first 10 models were rejected and the data were collected from the 11th model. Altogether, 10 experimental samples were collected. Three experimental samples were taken randomly from the same cavity and the drifted ones were eliminated. The experimental samples are shown in Fig. 7.

\subsection{Injection molding experiment with supersonic waves}

\subsubsection{Single-factor test of supersonic wave duration}

The durations of the supersonic wave were 1,3 , and $5 \mathrm{~s}$, the supersonic wave power was $30 \mathrm{~W}$, and the other parameters were set such that the optimal combination of the process parameters was obtained. The parts processed with the three durations of the supersonic waves are shown in Fig. 8.

\subsubsection{Single-factor test of supersonic power}

The supersonic wave powers were 25,30 , and $35 \mathrm{~W}$, the supersonic duration was $5 \mathrm{~s}$, and the other parameters were set such that the optimal combination of the process parameters was obtained. The parts processed with the three supersonic wave powers are shown in Fig. 9.

\subsection{Filling quality inspection of the molded products}

To better compare and analyze the filling rates of the molded parts with and without supersonic vibration, the quantities of samples in each group were determined using a precision electronic balance. The average values of each sample group are plotted in Fig. 10. The rate of change of the average filling quality with and without supersonic vibration is shown in Table 6.

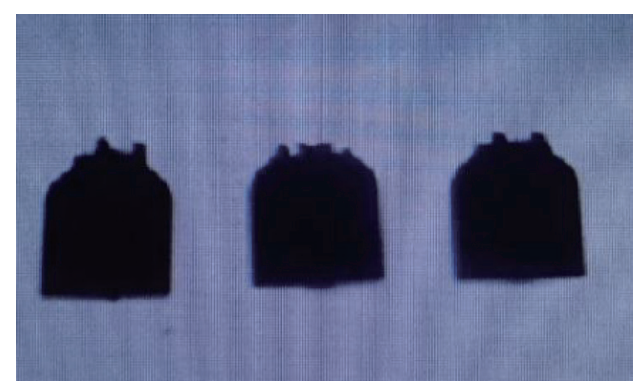

Fig. 7. (Color online) Experimental samples without supersonic vibration.

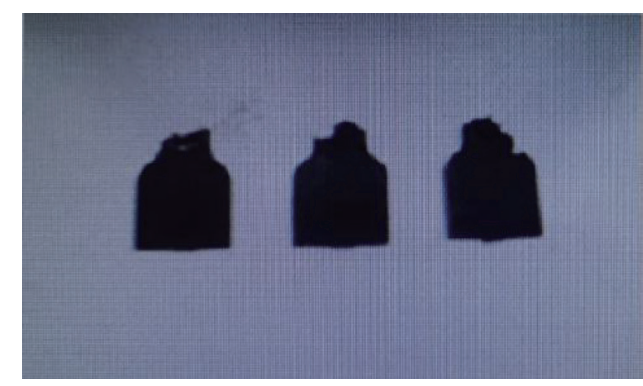

Fig. 8. (Color online) Products formed with the supersonic wave duration as the variable. From left to right: supersonic wave durations were 1,3 , and $5 \mathrm{~s}$. 


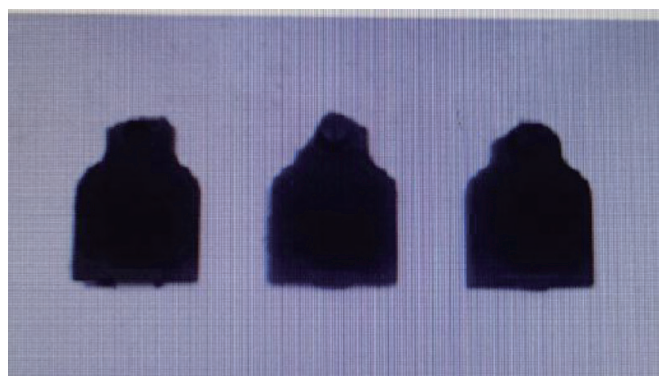

Fig. 9. (Color online) Products formed with the supersonic wave power as the variable. From left to right: supersonic wave powers were 25,30 , and $35 \mathrm{~W}$.

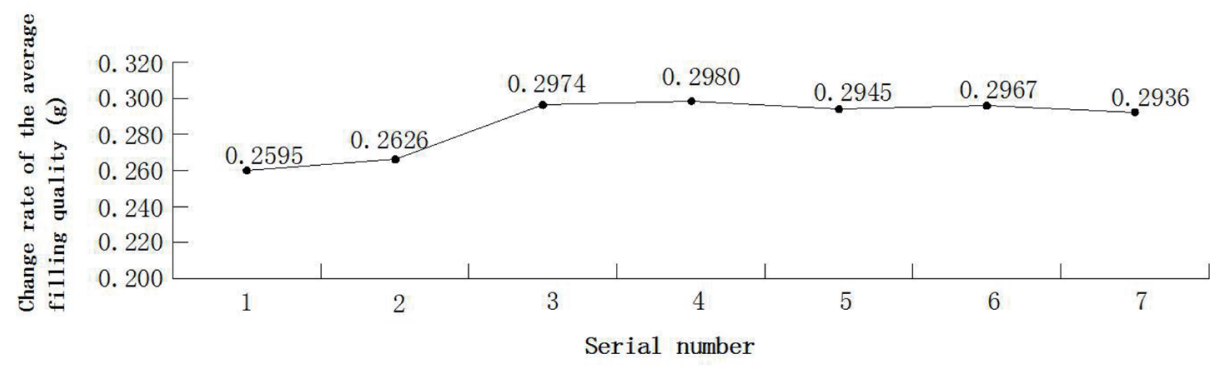

Fig. 10. Average filling mass of each experimental group.

Table 6

Rate of change of the filling quality.

\begin{tabular}{lcccccc}
\hline \multirow{2}{*}{ Serial No. } & \multicolumn{7}{c}{ Supersonic wave action } \\
\cline { 2 - 7 } & Supersonic & Supersonic & Supersonic & Supersonic & Supersonic & Supersonic \\
Parameters & wave $35 \mathrm{~W} / 1 \mathrm{~s}$ & wave $35 \mathrm{~W} / 3 \mathrm{~s}$ & wave $35 \mathrm{~W} / 5 \mathrm{~s}$ & wave $5 \mathrm{~s} / 25 \mathrm{~W}$ & wave $5 \mathrm{~s} / 30 \mathrm{~W}$ & wave $5 \mathrm{~s} / 35 \mathrm{~W}$ \\
Deviation (g) & 0.0030 & 0.0432 & 0.0455 & 0.0411 & 0.0425 & 0.0393 \\
Rate of change (\%) & $1.208 \%$ & $14.592 \%$ & $14.851 \%$ & $13.481 \%$ & $14.351 \%$ & $13.138 \%$ \\
\hline
\end{tabular}

From Fig. 10 and Table 6, it can be seen that, compared with the parts obtained by conventional injection molding (without supersonic vibration), the filling quality of the molded parts with supersonic vibration is clearly improved. This is because under the conventional injection molding conditions, the cavity of the thin-wall molded parts is small with a small volume, which causes a large filling resistance and rapid cooling, causing the melt viscosity to increase. Moreover, an excessively high melt viscosity reduces the filling fluidity of the high polymer melt, then, the cavity may not be completely filled, causing the occurrence of short shots. When the supersonic vibration field is added, the high-frequency vibration of the supersonic vibrator comes in contact with the low-temperature melt at the flow front, reactivating the macromolecular chain at the flow front of the low-temperature melt. This causes the molecular chain in the melt to wriggle, which decreases the number of chain entanglement points, thereby decreasing the melt viscosity and increasing the slip velocity of the melt along the wall. ${ }^{(15-17)}$ Moreover, the thermal effect of supersonic vibration increased the temperature of the melt, enabling the melt to continue to fill the cavity. Consequently, the filling quality is improved. 


\section{Conclusions}

(1) Because of poor fluidity, high cooling speed, and small cavity volume, the modified glassfiber-enhanced PBT melt exhibits a large flow resistance in thin-wall microinjection molding, which might affect the filling effect. When a supersonic vibration field was applied to polymer molding, the high-frequency supersonic vibration of the supersonic wave continuously squeezed and released the polymer melt. This not only lowered the viscosity of the polymer melt and improved its fluidity, but also reduced the energy consumption and shortened the molding cycle so that a mathematical model of the supersonic-assisted polymer melt flow in a microchannel could be constructed, and uneven filling in the injection molding could be prevented.

(2) The Cross-WLF model-based viscosity model of the flow behavior of the macromelt under the microstructural injection molding flow condition was fitted and modified. Through CAE simulation, mold flow analysis, and orthogonal experiment, on the premise of accurate control of the cavity pressure, the effect of injection molding parameters on the injection molding of glass-fiber-enhanced PBT was analyzed, and the optimal combination of molding technological parameters was obtained.

(3) A thin-wall microinjection molding experiment was conducted on glass-fiber-enhanced PBT materials using a supersonic-vibration-assisted thin-wall microinjection molding system, and the appearance and filling qualities of the parts molded in supersonic and nonsupersonic vibration fields were compared. The results revealed that the filling quality of the parts molded with supersonic vibration is higher than that of parts molded without supersonic vibration.

\section{Acknowledgments}

This work was partially sponsored by the Natural Science Foundation of Fujian Province, China (2019J01709).

\section{References}

1 W. B. Young: Microsyst. Technol. 11 (2005) 410. https://doi.org/10.1007/s00542-004-0474-4

2 M. Buchmann, R. Theriault, and T. A. Osswald: Polym. Eng. Sci. 37 (2004) 667. https://doi.org/10.1002/ pen. 11710

3 V. Piotter, T. Hanemann, R. Ruprecht, and J. Haußelt: Microsys. Technol. 3 (1997) 129.

4 J. Giboz, T. Copponnex, and M. Patrice: Micromech. Microeng. 17 (2007) 96. https://doi.org/10.1088/09601317/17/6/R02

5 B. Peng, H. Wu, S. Guo, S. Y. Lai, and J. Jow: Polym. Degrad. Stabil. 92 (2007) 1632. https://doi.org/10.1016/ j.polymdegradstab.2007.03.025

6 H. Pelletier, C. Gauthier, and R. Schirrer: Tribol. Lett. 37 (2010) 507. https://doi.org/10.1007/s11249-0099546-Z

7 L. Y. Yu, L. J. Lee, W. Kurt, and Koelling: Polym. Eng. Sci. 44 (2004) 1866. https://doi.org/10.1002/pen.20188

8 S. Biwa, Y. Watanabe, S. Motogi, and N. Ohno: Ultrasonics 43 (2004) 5. https://doi.org/10.1016/ j.ultras.2004.03.002

9 C. Lu, X. F. Yu, and S. Y. Guo: Polym. Eng. Sci. 45 (2005) 1666. https://doi.org/10.1002/pen.20456

10 M. Rath, J. Döring, W. Stark, and G. Hinrichsen: NDT and E Int. 33 (2000) 123. https://doi.org/10.1016/S09638695(99)00029-8 
11 R. D. Chien, W. R. Jong, and S. C. Chen: J. Micromech. Microeng. 15 (2005) 1389. https://doi. org/10.1088/0960-1317/15/8/003

12 H. Hervet and L. Leger: C. R. Phys. 4 (2003) 241. https://doi.org/10.1016/S1631-0705(03)00047-1

13 J. Li, S. Y. Guo, R. Slazak, and B. Hausnerová: Macromol. Chem. Phys. 206 (2005) 2429. https://doi. org/10.1002/macp.200500311

14 J. Lee and N. Kim: Mater. Process. Technol. 201 (2007) 710. https://doi.org/10.1016/j.jmatprotec.2007.11.295

15 H. Mekaru, H. Goto, and M. Takahashi: Microelectron. Eng. 84 (2007) 1282. https://doi.org/10.1016/ j.mee.2007.01.235

16 A. Sato, H. Ito, and K. Koyama: Polym. Eng. Sci. 49 (2010) 768. https://doi.org/10.1002/pen.21268

17 N. T. Nguyen, M. Lethiecq, and J. F. Gerard: Ultrasonics 33 (1995) 323. 